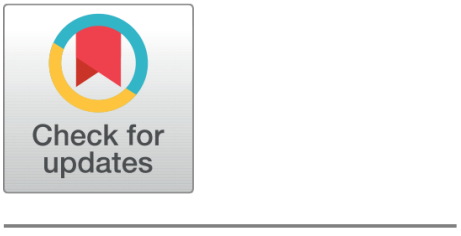

OPEN ACCESS

Received: 11.06.2021

Accepted: 16.09.2021

Published: 15.11.2021

Citation: Kumari SC, Selvakumar V, Naga Padma P, Anuradha K (2021) Optimization Studies on Green Synthesis of Silver Nanoparticles from different Plant Extracts Using Taguchi Design. Indian Journal of Science and Technology 14(38): 2888-2898. https://doi.org/ 10.17485/IJST/v14i38.1065

* Corresponding author.

anuradhapmv@gmail.com

Funding: None

Competing Interests: None

Copyright: ๑ 2021 Kumari et al. This is an open access article distributed under the terms of the Creative Commons Attribution License, which permits unrestricted use, distribution, and reproduction in any medium, provided the original author and source are credited.

Published By Indian Society for Education and Environment (iSee)

ISSN

Print: 0974-6846

Electronic: 0974-5645

\section{Optimization Studies on Green Synthesis of Silver Nanoparticles from different Plant Extracts Using Taguchi Design}

\author{
S Chaitanya Kumari ${ }^{1}$, V Selvakumar ${ }^{2}$, P Naga Padma1 ${ }^{1}$ K Anuradha ${ }^{1 *}$ \\ 1 Department of Microbiology, Bhavan's Vivekananda College of Science, Humanities \& \\ Commerce, Sainikpuri, Sec-bad, 500094, Telangana, India \\ 2 Department of Maths and Statistics, Bhavan's Vivekananda College of Science, Humanities \\ \& Commerce, Sainikpuri, Sec-bad, 500094, Telangana, India
}

\section{Abstract}

Background/Objectives: The main objective of the present study is to screen an efficient plant extract sources for the green synthesis of silver nanoparticles (AgNPs) and optimization of various conditions for the synthesis using a statistical methodology like Taguchi design. The antimicrobial activity of the synthesized AgNPs against common wound causing dermal pathogens was also checked. Methods: The conditions for green synthesis, such as the concentration of silver nitrate, amount of plant extract, synthesis reaction time, temperature, and $\mathrm{pH}$ of the plant extract, were optimized by using Taguchi design ( $\mathrm{L}_{27}$ type). Ultraviolet-visible spectroscopy, scanning electron microscopy (SEM), and Transmission electron microscopy (TEM) were used for the characterization of produced green AgNPs. The antibacterial activity of the obtained green AgNPs was tested against most common wound forming dermal pathogens like $S_{1}$ (Staphylococcus aureus-Multi drug-resistant, hospital strain), $\mathrm{S}_{2}$ (Staphylococcus aureus-pimple source), $\mathrm{S}_{3}$ (Staphylococcus aureuswound sample), $\mathrm{S}_{4}$ (Pseudomonas sp.-hospital sample), and $\mathrm{S}_{5}$ (Pseudomonas $s p$.-wound sample) using Agar well diffusion method. Findings: Thirty different aqueous leaf extracts were screened for AgNPs using a flask level unidimensional study. Among all, the aqueous leaf extract of Aloe vera was found to be the most suitable for the green synthesis of AgNPs. The optimum conditions for the green synthesis of AgNPs were observed as $\mathrm{pH}$ - 7.0, temperature $35^{\circ} \mathrm{C}, 10 \mathrm{mM}$ silver nitrate $\left(\mathrm{AgNO}_{3}\right), 50 \%(\mathrm{v} / \mathrm{v})$ plant extract for a time period of 30 min. Novelty/Applications: The Taguchi statistical method was used for the optimization of the green synthesis of AgNPs with suitable experiential tests. Finally, this rapid and easy process of green synthesis of AgNPs using aqueous leaf extract of Aloe vera demonstrated broad spectrum activity as an antibacterial agent against the wound-causing dermal pathogens in the medical field by exhibiting the promising minimum inhibitory concentration (MIC) of AgNPs as $\leq 0.0535 \mathrm{mg} / \mathrm{L}$. 
Keywords: Green synthesis; silver nanoparticles; Statistical optimization; Taguchi method Antibacterial activity

\section{Introduction}

Metallic nanoparticles have huge consideration deductively and innovatively because of their extraordinary and strange physico-chemical properties when contrasted with mass materials ${ }^{(1,2)}$. The green synthesis of nanoparticles using both microbial sources like bacteria ${ }^{(3)}$, fungi ${ }^{(4)}$, yeast ${ }^{(5)}$, and plant materials ${ }^{(6,7)}$ have gained prominence as they are clean, nonhazardous, and eco-friendly when compared to physical and chemical methods ${ }^{(8,9)}$. Among these green methods, microorganisms intervened synthesis of nanoparticles isn't industrially reasonable as maintenance of culture and fermentative process require profoundly sterile conditions ${ }^{(10)}$.Additionally, the reduction of metallic ions by microbes requires longer incubation time as compared to plant extracts ${ }^{(11)}$. The utilization of plant extracts is additionally gainful over microorganisms because of the easiness to scale-up ${ }^{(12)}$. The plant extracts can be used both intracellularly and extracellularly for the synthesis of different nanoparticles ${ }^{(13-15)}$. The intracellular synthesis includes growing plants in metal-rich media or soil ${ }^{(16,17)}$, whereas extracellular methods include boiling the plant material in sterile water or any organic solvent ${ }^{(18,19)}$.

Many researchers have focused on AgNPs due to their significant applications in color filters, optical switching, optical sensors, surface-enhanced Raman scattering, etc. ${ }^{(20-22)}$ and also in clothing, respirators, household water filters, antibacterial sprays, cosmetics, detergents, dietary supplements, cutting boards, shoes, cell phones, laptop keyboards, and children toys are typical products currently in the market that exploit the antimicrobial properties of silver nanoparticles ${ }^{(23-25)}$.Taking their multiple applications into consideration, the annual synthesis of silver nanoparticles has been estimated to be 55 tons globally, and this is increasing according to the demand ${ }^{(26,27)}$.

The present work focused on the application of statistical experimental designing tools for green synthesis of AgNPs using different plant extracts. The synthesis process of these nanoparticles involves the reduction of silver ions, nucleation, and growth of the particles ${ }^{(28)}$ that is influenced by several factors like the amount of both silver nitrate and plant extract, $\mathrm{pH}$, incubation period, temperature, etc. ${ }^{(29,30)}$. By implementing statistical tools for the synthesis of nanoparticles specifically for regulating the size is resulted in enhancing bioactive attributes of the synthesized AgNPs. A statistical method Taguchi was applied to minimize the number of experiential trails during optimizing different parameters for efficient green synthesis of AgNPs. Taguchi is a basic and powerful measurable strategy that arranges orderly experimentation to decide the close to ideal settings of plan parameters for execution, quality, and cost. Right now, a huge number of factors are concentrated with few tests utilizing symmetrical exhibits, and the fluctuation of parameters is communicated by signal-to-noise $(\mathrm{S} / \mathrm{N})$ proportion, which represents the ratio of desirable results (signal) to undesirable results (noise). Thus, the optimized parameters would help in the bulk synthesis of AgNPs by the green method.

\section{Materials and Methods}

\subsection{Preparation of Plant Extract}

Fresh leaves of different plants (Table 1) were collected from different areas like the college campus, local garden, and nursery. The leaves were washed thoroughly, cut, and dried. Approximately $20 \mathrm{~g}$ of the dried powder of respective plant sp. were boiled in $100 \mathrm{ml}$ of double-distilled water for $10-15 \mathrm{~min} .{ }^{(31)}$. The aqueous solution was filtered 
and stored at $40^{\circ} \mathrm{C}$ until further use.

Table 1. Different plant species used for green synthesis of silver nanoparticles

\begin{tabular}{|c|c|c|}
\hline & Plant species & \\
\hline S.No & Scientific name & Common name \\
\hline 1 & Amaranthus & Pigweed \\
\hline 2 & Aloe vera & First aid plant \\
\hline 3 & Annona reticulata & Custard apple \\
\hline 4 & Calotropis & Jilledu \\
\hline 5 & Carica papaya & Papaya \\
\hline 6 & Chrysanthemum & Chamanthi \\
\hline 7 & Cinnamomum tamala & Bay leaf \\
\hline 8 & Citrus limon (L.) & Lemon \\
\hline 9 & Coriandrum sativum & Coriander \\
\hline 10 & Curcuma longa & Turmeric \\
\hline 11 & Eucalyptus globulus & Southern blue gum \\
\hline 12 & Lawsonia inermis & Henna \\
\hline 13 & Mentha & Pepper mint \\
\hline 14 & Millettia pinnata & Indian beech \\
\hline 15 & Mirabilis jalapa & 4'o clock plant \\
\hline 16 & Momordica charantia Linn. & Karela \\
\hline 17 & Moringa oleifera & Drum stick \\
\hline 18 & Murraya koenigii & Curry leaf \\
\hline 19 & Nerium oleander & Nerium \\
\hline 20 & Ocimum basilicum & Basil \\
\hline 21 & Phyllanthus emblica & Amla \\
\hline 22 & Piper betle & Tamalapaku \\
\hline 23 & Psidium guajava & Guava \\
\hline 24 & Punica granatum & Pomegranate \\
\hline 25 & Ricinus communis & Castor bean \\
\hline 26 & Sapindus mukorossi & Soap berry \\
\hline 27 & Syzygium cumini & Malabar plum \\
\hline 28 & Tagetes & Marigold \\
\hline 29 & Trigonella foenum-graecum & Fenugreek \\
\hline 30 & Zingiber officinale & Ginger \\
\hline
\end{tabular}

\subsection{Green synthesis of silver nanoparticles and optimization experiments}

The silver nanoparticles were synthesized by adding both silver nitrate solution and aqueous plant extract at various concentrations. These reaction mixtures were incubated at different time intervals and different temperatures and $\mathrm{pH}$ (Table 2). The experiment was performed in duplicates (set A and set B).

Table 2. Parameters with their levels used for green synthesis of silver nanoparticles

\begin{tabular}{|c|c|c|c|c|}
\hline \multirow{2}{*}{ Factc } & & \multicolumn{3}{|c|}{ Levels } \\
\hline & & $1^{\text {st }}$ & $2^{\text {nd }}$ & $3^{\text {rd }}$ \\
\hline A & Concentration of $\mathrm{AgNO}_{3}(\mathrm{mM} / \mathrm{ml})$ & 2 & 5 & 10 \\
\hline B & Concentration of plant extract $(\mathrm{ml})$ & 25 & 50 & 75 \\
\hline $\mathrm{C}$ & $\mathrm{pH}$ & 5 & 7 & 9 \\
\hline $\mathrm{D}$ & Incubation time period $(\mathrm{min})$ & 10 & 30 & 60 \\
\hline $\mathrm{E}$ & Incubation temperature $\left({ }^{0} \mathrm{C}\right)$ & 25 & 35 & 50 \\
\hline
\end{tabular}

The design of an experiment is a powerful tool to conduct experiments with minimum resources. Therefore, the experimental parameters were studied using a statistical design called the Taguchi method. The parameters and their levels were set up based on the selected Taguchi design, as indicated in Table 2. The variables like the amount of silver nitrate and plant extract, incubation period, incubation temperature, and $\mathrm{pH}$ were studied at levels 1, 2, and 3. The Taguchi orthogonal matrix, $\mathrm{L}_{27}$, was used for designing the experimental trials considering the mentioned five variables at three different levels. The experimental 
results obtained were subjected to analysis. Data processing is done by estimating the $\mathrm{S} / \mathrm{N}$ ratio, which is the ratio of the target value to the deviation from its mean. In the Taguchi design, the target value (mean) represents the signal, and the standard deviation for the response variable represents Noise. For calculating the $\mathrm{S} / \mathrm{N}$ ratio, the larger-the-better quality characteristic is selected, and it is calculated by using the following equation (1).

$$
\frac{S}{N}_{\text {Larger the better }}=-10 \log \left\{\frac{1}{n} \sum_{i=1}^{n} \frac{1}{y_{i}^{2}}\right\}
$$

Where $\mathrm{n}$ is the number of experiments, $\mathrm{y}_{i}$ is the response variable for the $\mathrm{i}^{\text {th }}$ experiment

\subsection{Green synthesis of silver nanoparticles and optimization experiments}

The synthesized silver nanoparticles were centrifuged at $15000 \mathrm{rpm}$ for 5-10min, and the obtained nanoparticles pellet was washed with ethanol solution twice and dried in a microwave oven to obtain a powdered form of nanoparticles.

\subsection{Characterization of synthesized silver nanoparticles}

The reduction of pure Ag+ particles was observed by estimating the UV-Vis range of the response. UV-Vis absorption spectrum of the samples is determined at a wavelength of $450 \mathrm{~nm}$, which was obtained as absorption maxima (300-500nm). The morphology and size of the obtained AgNPs were analyzed by using a Scanning electron microscope (SEM) and Transmission electron microscope (TEM) (SEM: Hitachi S3700N and TEM: Tecnai-12 FEI at Osmania University College of technology, Hyderabad).

\subsection{Antimicrobial susceptibility testing}

Agar well diffusion method was used to check the antibacterial activity of the obtained AgNPs. The most common wound forming dermal pathogens like $\mathrm{S}_{1}$ (Staphylococcus aureus-Multi drug-resistant, hospital strain), $\mathrm{S}_{2}$ (Staphylococcus aureuspimple source), $\mathrm{S}_{3}$ (Staphylococcus aureus-wound sample), $\mathrm{S}_{4}$ (Pseudomonas sp.-hospital sample), and $\mathrm{S}_{5}$ (Pseudomonas sp.wound sample) were tested for their response to the green synthesized AgNPs. Standard drug (ampicillin $125 \mu \mathrm{g} / \mathrm{mL}$ ) and deionized water were used as a positive and negative control, respectively. The zones of inhibition $(\mathrm{cm})$ were obtained after post-incubation at $37^{\circ} \mathrm{C}$ for $24 \mathrm{hrs}$. The experiment was carried in triplicates.

\section{Results and Discussion}

The AgNPs were synthesized using different plant extracts as listed in Table 1 as reducing and stabilizing agents, the aqueous silver nitrate solution turned to brown color upon incubation, which is the first visual indication for the formation of nanoparticles (Figure 1). Out of thirty different plant extracts, fifteen plant extracts showed significant results depending upon the rate of reduction of silver ions (Figure 2). Among the effective fifteen samples aqueous Aloe vera extract exhibited the maximum reduction of silver ions indicated by the highest absorbance value as 0.68 . This may be due to the presence of biologically active constituents includes amino acids, enzymes, vitamins like A, C, E, quinones, lignin, sugars, salicylic acid, saponins, sterols ${ }^{(32)}$ which also prevents aggregation of nanoparticles ${ }^{(33)}$ and especially hydroquinone's in Aloe vera plant extract acts as the reducing agent ${ }^{(34)}$.

Characterization studies of metallic nanoparticles are essential to comprehend their properties and applications ${ }^{(35,36)}$. AgNPs formation is primarily confirmed by the UV-Visible spectroscopy technique ${ }^{(37)}$ where absorption values in the wavelength ranges of $300-500 \mathrm{~nm}$ are used ${ }^{(38)}$. Silver nanoparticles at the nano range display an interesting optical phenomenon called surface Plasmon resonance (SPR) because of the total swaying of the directing metal surface electrons in resonance with the non-particulate radiation. This property was generally dependent upon the molecule type, size, shape, and local chemical nature. The absorption spectra of the AgNPs synthesized with Aloe vera extract were observed at 450nm, as indicated in Figure 3. The Scanning electron microscopy (SEM) analysis for size determination indicated that AgNPs with Aloe vera extract were spherical with a size range variation of 43.3-63.0 $\mathrm{nm}$ in diameter (Figure 4), and larger AgNPs could be due to an increase in the concentration of silver nitrate solution. The shape, size, and morphology of the green synthesized AgNPs were elucidated with the help of Transmission electron microscopy (TEM), further confirming the formation of silver nanoparticles. TEM images (Figure 5) of the sample also showed nanoparticles exhibiting a typical spherical morphology with a size range of 50nm. There 


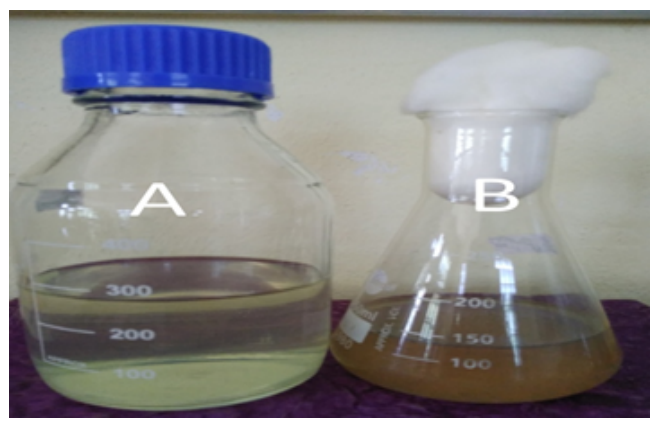

Fig 1. (A) Mixture of plant extract \& silver nitrate, (B) Formation of silver nanoparticles

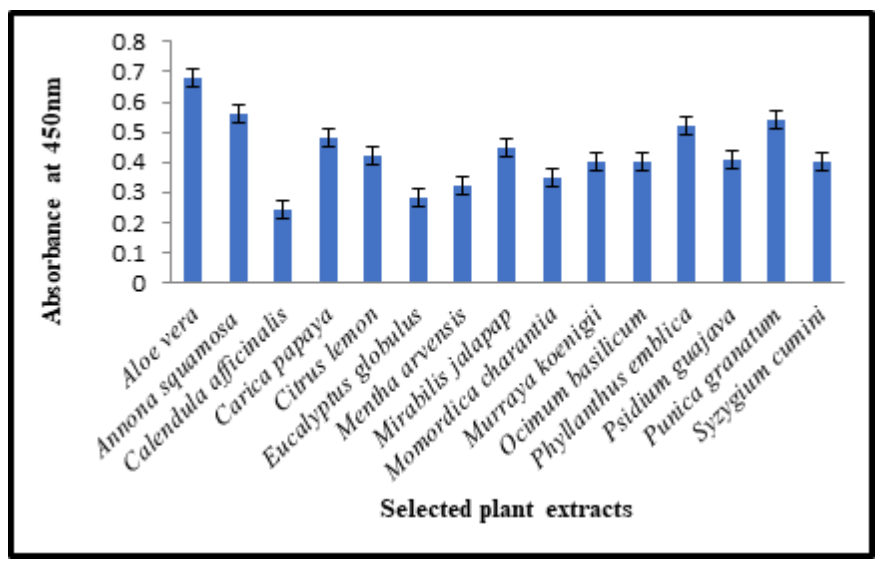

Fig 2. Absorbance of green synthesized AgNPs from various plant extracts

are similar such reports by Patcharaporn Tippayawat et al., who worked on Aloe vera extract and indicated the formation of spherical AgNPs with a size of $192.02-70.7 \mathrm{~nm}^{(39)}$.

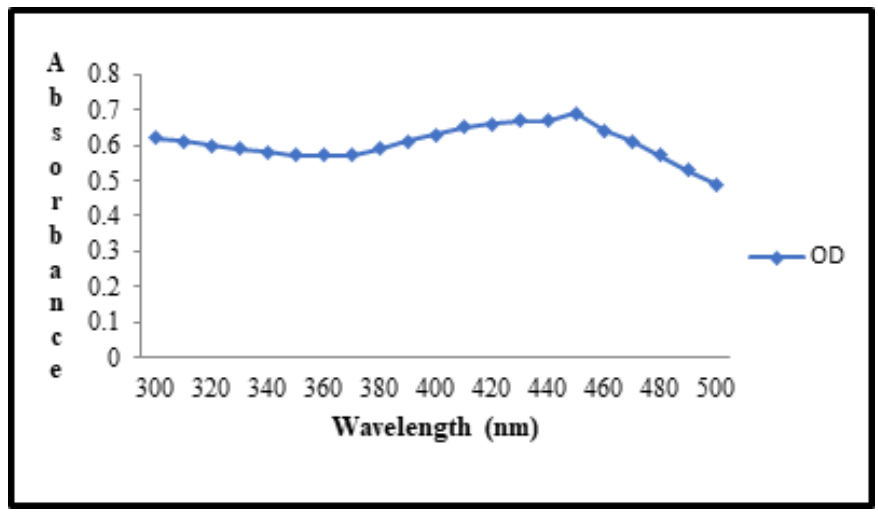

Fig 3. UV-Visible spectroscopy of AgNPs synthesized from Aloe vera plant extract 

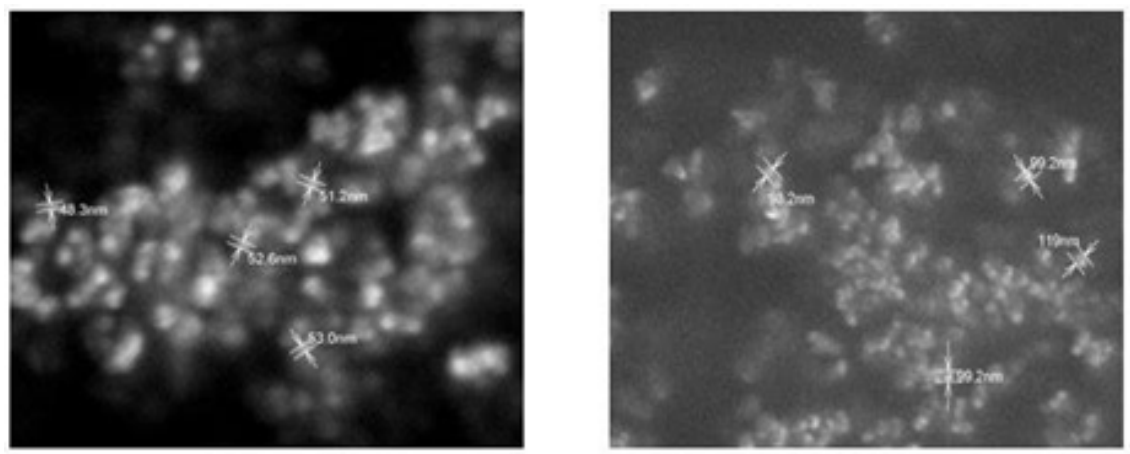

Fig 4. SEM image of green synthesized silver nanoparticles

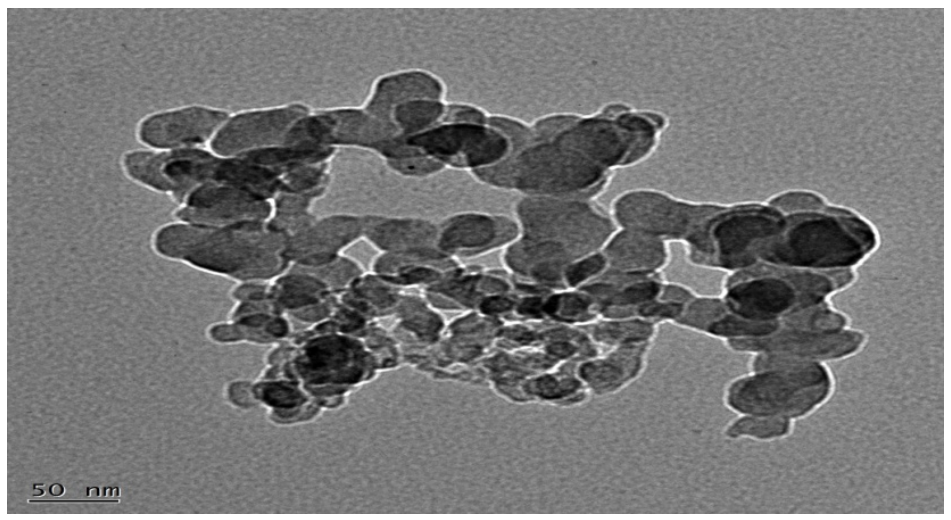

Fig 5. TEM image of green synthesized silver nanoparticles

\subsection{Taguchi Experimental Design:}

$\mathrm{L}_{27}$ orthogonal array design was used to study five variables at different levels (Table 3). The experimental results were statistically analyzed, and the main effect of each variable is indicated in the graphical plot (Figure 6).

Table 3. Taguchi $\mathrm{L}_{27}$ orthogonal array design experimental set up for green synthesis of sliver nano

\begin{tabular}{lllllll}
\hline \multirow{2}{*}{ Level } & \multicolumn{7}{c}{ Factors } & E & \multirow{2}{*}{ Average of set-A\&B (OD values at 450nm) } \\
\cline { 2 - 5 } & $\mathrm{A}$ & $\mathrm{B}$ & $\mathrm{C}$ & $\mathrm{D}$ & $\mathrm{RT}$ & 0.12 \\
$\mathrm{~L}_{1}$ & 2 & 25 & 5 & 10 & 35 & 0.14 \\
$\mathrm{~L}_{2}$ & 2 & 25 & 5 & 10 & 50 & 0.08 \\
$\mathrm{~L}_{3}$ & 2 & 25 & 5 & 10 & $\mathrm{RT}$ & 0.38 \\
$\mathrm{~L}_{4}$ & 2 & 50 & 7 & 30 & 35 & 0.46 \\
$\mathrm{~L}_{5}$ & 2 & 50 & 7 & 30 & 50 & 0.31 \\
$\mathrm{~L}_{6}$ & 2 & 50 & 7 & 30 & $\mathrm{RT}$ & 0.09 \\
$\mathrm{~L}_{7}$ & 2 & 75 & 9 & 60 & 35 & 0.23 \\
$\mathrm{~L}_{8}$ & 2 & 75 & 9 & 60 & 50 & 0.14 \\
$\mathrm{~L}_{9}$ & 2 & 75 & 9 & 60 & $\mathrm{RT}$ & 0.18 \\
$\mathrm{~L}_{10}$ & 5 & 25 & 5 & 10 & 35 & 0.26 \\
$\mathrm{~L}_{11}$ & 5 & 25 & 5 & 10 & 50 & 0.14 \\
$\mathrm{~L}_{12}$ & 5 & 25 & 5 & 10 & $\mathrm{RT}$ & 0.42 \\
$\mathrm{~L}_{13}$ & 5 & 50 & 7 & 30 & 35 & 0.56 \\
$\mathrm{~L}_{14}$ & 5 & 50 & 7 & 30 & 50 & 0.38 \\
$\mathrm{~L}_{15}$ & 5 & 50 & 7 & 30 & $\mathrm{RT}$ & 0.1 \\
$\mathrm{~L}_{16}$ & 5 & 75 & 9 & 60 & 35 & 0.23 \\
$\mathrm{~L}_{17}$ & 5 & 75 & 9 & 60 & & \\
\hline
\end{tabular}

Continued on next page 


\begin{tabular}{lllllll}
\hline \multicolumn{7}{c}{ Table 3 continued } \\
\hline $\mathrm{L}_{18}$ & 5 & 75 & 9 & 60 & 50 & 0.11 \\
$\mathrm{~L}_{19}$ & 10 & 25 & 5 & 10 & $\mathrm{RT}$ & 0.21 \\
$\mathrm{~L}_{20}$ & 10 & 25 & 5 & 10 & 35 & 0.32 \\
$\mathrm{~L}_{21}$ & 10 & 25 & 5 & 10 & 50 & 0.21 \\
$\mathrm{~L}_{22}$ & 10 & 50 & 7 & 30 & $\mathrm{RT}$ & 0.76 \\
$\mathrm{~L}_{23}$ & 10 & 50 & 7 & 30 & 35 & 0.9 \\
$\mathrm{~L}_{24}$ & 10 & 50 & 7 & 30 & 50 & 0.58 \\
$\mathrm{~L}_{25}$ & 10 & 75 & 9 & 60 & $\mathrm{RT}$ & 0.12 \\
$\mathrm{~L}_{26}$ & 10 & 75 & 9 & 60 & 35 & 0.24 \\
$\mathrm{~L}_{27}$ & 10 & 75 & 9 & 60 & 50 & 0.16 \\
\hline
\end{tabular}

RT-Room temperatures, A- Concentration of AgNO3, B- Concentration of plant extract, C- $\mathrm{pH}$, D- Incubation time period, E- Incubation temperature, OD-Absorbance

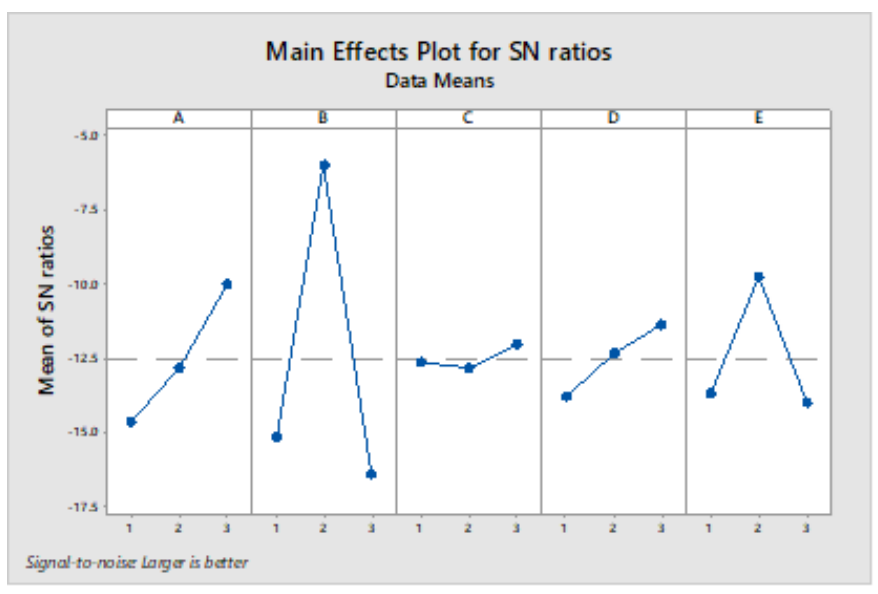

Fig 6. Taguchi design - Main effects Plot of Mean of S/N Ratio for the synthesis of AgNPs

\subsection{Taguchi Experimental Design:}

The quality characteristics "larger is better" from equation (1) were applied to the experimental data. From Figure 6, it was observed that the results based on the Signal to Noise Ratio (S/N), larger levels of factors A, B, C, D, and E give a comparatively greater production of AgNPs. Hence the optimal parameters for AgNPs production are observed as the incubation temperature of $35^{\circ} \mathrm{C}$, the amount of $\mathrm{AgNO}_{3}$ as $10 \mathrm{mM}$, the $\mathrm{pH}$ as seven, and the concentration of plant extract as $50 \mathrm{~mL}$ with an incubation period of $30 \mathrm{mins}$ as indicated in Table 4.

Table 4. Optimum values of factors and their levels

\begin{tabular}{lll}
\hline & \multicolumn{1}{c}{ Factor } & Optimum Value \\
\hline $\mathrm{A}$ & Concentration of $\mathrm{AgNO}_{3}(\mathrm{mM} / \mathrm{ml})$ & $10 \mathrm{mM} / \mathrm{ml}$ \\
$\mathrm{B}$ & Concentration of plant extract $(\mathrm{ml})$ & $50 \mathrm{ml}$ \\
$\mathrm{C}$ & $\mathrm{pH}$ & 7 \\
$\mathrm{D}$ & Incubation time period $(\mathrm{min})$ & $30 \mathrm{~min}$ \\
$\mathrm{E}$ & Incubation temperature $\left({ }^{0} \mathrm{C}\right)$ & $35^{0} \mathrm{C}$ \\
\hline
\end{tabular}

Metal nanoparticle synthesis and their characteristics were influenced by different parameters like concentration of silver nitrate, amount of plant extract, incubation period, and temperature. Their optimization studies, if done by a traditional unidimensional approach where one variable at a time is evaluated, keeping remaining variables constant would be both times consuming and laborious. Another major disadvantage is that it does not show what would happen if the other variables are 
also changing simultaneously. Very few reports are available on the development of a protocol to obtain smaller size AgNPs using green synthesis by the Taguchi method ${ }^{(40)}$.

Therefore, our study focused on robust design, the central theme of the Taguchi method, which emphasis on to make the process insensitive to those sources of variations. Therefore, Taguchi's statistical approach would be both time saving and costeffective, and it gives scope for the study of different parameters and different levels in one experiment. The use of linear graphs and triangular tables suggested by Taguchi makes the assignment of parameters simple.

\subsection{Antimicrobial activity:}

The green synthesized AgNPs from aqueous Aloe vera plant extract exhibited considerably significant antibacterial activity against common wound forming dermal pathogens like $\mathrm{S}_{1}$ (Staphylococcus aureus-Multi drug-resistant, hospital strain), $\mathrm{S}_{2}$ (Staphylococcus aureus-pimple source), $\mathrm{S}_{3}$ (Staphylococcus aureus-wound sample), $\mathrm{S}_{4}$ (Pseudomonas sp.-hospital sample) and $\mathrm{S}_{5}$ (Pseudomonas sp.-wound sample) (Figure 7). The results indicate that AgNPs have higher antibacterial activity against multidrug-resistant bacteria $S$. aureus $S_{1}$ (isolate 1) over the other pathogens (Figure 8). The obtained zones of inhibition when compared with the standard drug (ampicillin), it was found that only Aloe vera leaf extract was not very much effective, but the synthesized AgNPs were resulted as strong as the standard drug. Based on these observations, the minimum inhibitory concentration (MIC) of AgNPs is $\leq 0.0535 \mathrm{mg} / \mathrm{L}$ which may be due to uniform and predominant nano size silver metal ions that are synthesized using controlled statistical design of experiments.

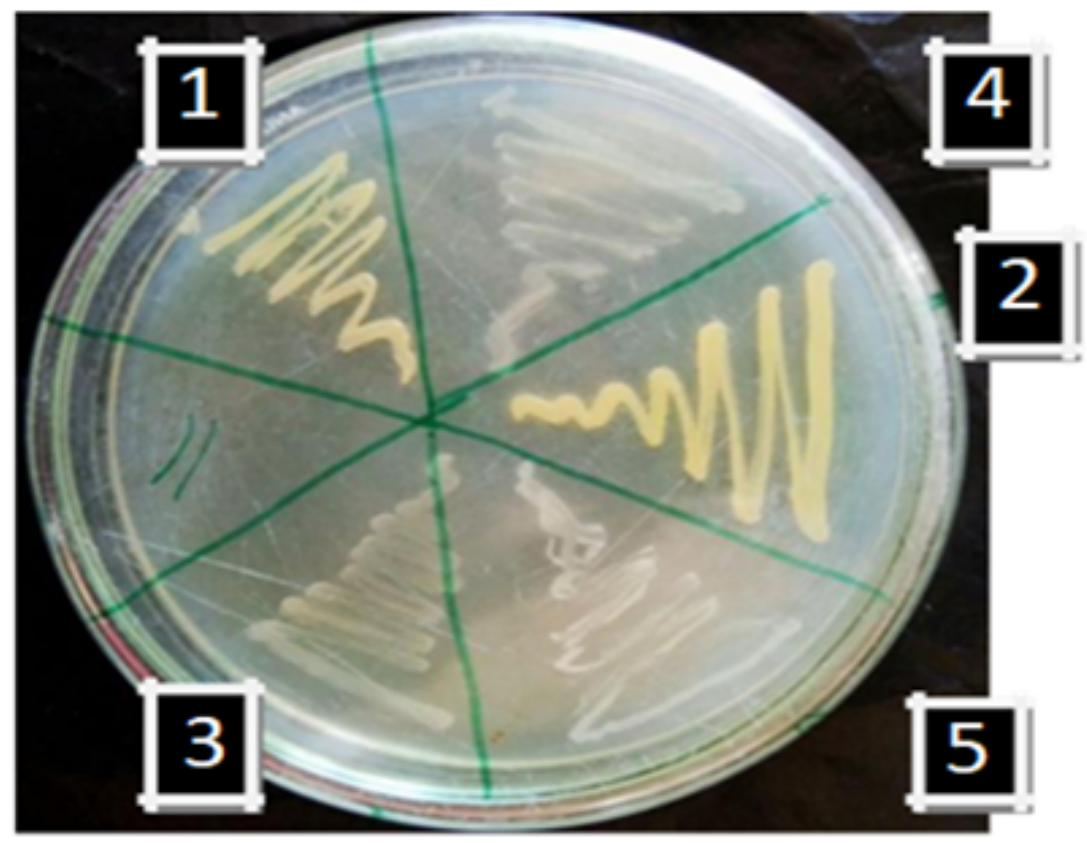

Fig 7. Common wound forming pathogens (isolate 1-S1 Staphylococcus aureus-Multi drug-resistant, hospital strain, isolate 2-S2 Staphylococcus aureus-pimplesource, isolate 3-S3 Staphylococcus aureus-wound sample, isolate 4-S4 Pseudomonas sp.-hospital sample, isolate 5-S5 Pseudomonas sp.-wound sample

Therefore, the antibacterial activity of green synthesized AgNPs using Aloe vera medicinal plant demonstrated antagonistic activity against both Gram-positive and Gram-negative wound forming bacteria. These results were agreed with the previous work carried out by Hungund et al., 2015; Balashanmugam et al., 2015, and Chitra et al., 2014. ${ }^{(41-43)}$

Hence the present study exhibits that a low concentration of AgNPs is alluring because of its expansive range of antibacterial action $^{(44,45)}$ and due to its bactericidal activity against multi drug resistant organisms like Methicillin-resistant $S$. aureus (MRSA), just as multidrug-resistant Pseudomonas $s p^{(46)}$. This might be because the positive charge on the Ag+ particle is critical for its antimicrobial property through the electrostatic fascination between the contrarily charged cell layer of the microorganisms and the decidedly charged nanoparticles. Accordingly, green synthesized AgNPs utilizing Aloe vera plant extract can likewise be utilized for other clinical applications. 


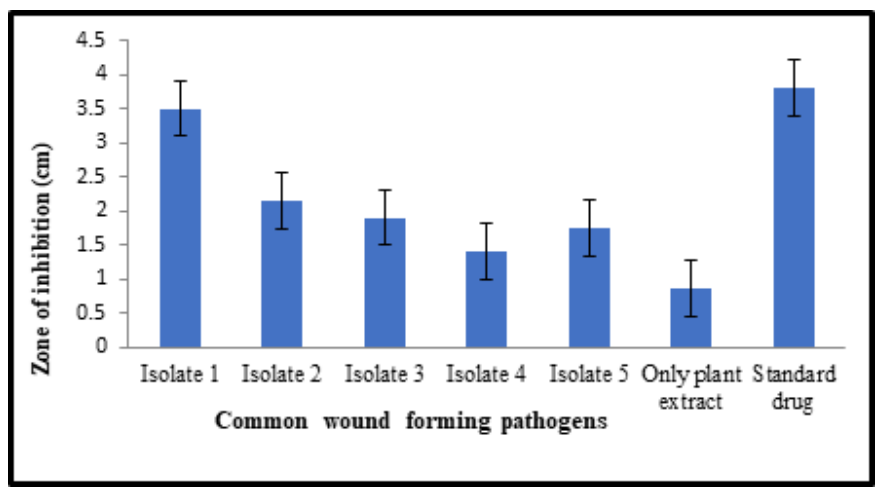

Fig 8. Antibacterial activities of green synthesized AgNPs against common wound forming pathogens

\section{Conclusion}

In the present study, AgNPs were synthesized by using green and eco-friendly technology, with qualitative data using statistical experimental design support. Our research concentrated on robust design, a vital concept of the Taguchi approach, which emphasizes the need to make the process insensitive to those sources of variation. As a result, Taguchi's $\mathrm{L}_{27}$ orthogonal array experimental design is applied to identify the effectiveness of every factor such as $\mathrm{AgNO}_{3}, \mathrm{pH}$, temperature, incubation time, and plant extract in the synthesis to obtain optimal values for the synthesis. AgNPs were observed as small, spherical in size 43.3-63.0 $\mathrm{nm}$ in diameter without any agglomeration. The AgNPs, which are produced by aqueous Aloe vera extract, demonstrated better results for broad-spectrum anti-bacterial activity against different bacteria strains selected for testing (Minimum inhibitory concentration (MIC) of AgNPs was found to be $\leq 0.0535 \mathrm{mg} / \mathrm{L}$ ). In the future, these non-toxic green synthesized AgNPs may have useful applications in the field of anti-bacterial formulations against various drug-resistant pathogens.

\section{References}

1) Bar H, Bhui DK, Sahoo GP, Sarkar P, De SP, Misra A. Green synthesis of silver nanoparticles using latex of Jatropha curcas. Colloids and Surfaces A: Physicochemical and Engineering Aspects. 2009;339(1-3):134-139. Available from: https://dx.doi.org/10.1016/j.colsurfa.2009.02.008.

2) Chung IM, Park I, Seung-Hyun K, Thiruvengadam M, Rajakumar G. Plant-Mediated Synthesis of Silver Nanoparticles: Their Characteristic Properties and Therapeutic Applications. Nanoscale Research Letters. 2016;11(1):40-54. Available from: https://dx.doi.org/10.1186/s11671-016-1257-4.

3) Navazi Z, Ranjbar M, Pazouki F, Halek S. Investigation of culture conditions for biosynthesis of silver nanoparticles using Aspergillus fumigates. Iran $J$ Biotechnol. 2010;8(1):56-61. Available from: http://www.ijbiotech.com/article_7105.html.

4) Hemath NK, Kumar G, Karthik L, Rao KVB. Extracellular biosynthesis of silver nanoparticles using the filamentous fungus Penicillium SPS. . Archives of Applied science Research. 2010;2:161-167. Available from: https://www.scholarsresearchlibrary.com/articles/extracellular-biosynthesis-ofsilver-nanoparticles- using-the-filamentous-fungus-penicillium-sp.pdf.

5) Kowshik M, Ashtaputre S, Kharrazi S, Vogel W, Urban J, Kulkarni SK, et al. Extracellular synthesis of silver nanoparticles by a silver-tolerant yeast strain MKY3. Nanotechnology. 2003;14(1):95-100. Available from: https://dx.doi.org/10.1088/0957-4484/14/1/321.

6) Abel S, Tesfaye JL, Shanmugam R, Dwarampudi LP, Lamessa G, Nagaprasad N, et al. Green Synthesis and Characterizations of Zinc Oxide (ZnO) Nanoparticles Using Aqueous Leaf Extracts of Coffee (Coffea arabica) and Its Application in Environmental Toxicity Reduction. Journal of Nanomaterials. 2021;2021:1-6. Available from: https://dx.doi.org/10.1155/2021/3413350.

7) Degefa A, Bekele B, Jule LT, Fikadu B, Ramaswamy S, Dwarampudi LP, et al. Green Synthesis, Characterization of Zinc Oxide Nanoparticles, and Examination of Properties for Dye-Sensitive Solar Cells Using Various Vegetable Extracts. Journal of Nanomaterials. 2021;2021:1-9. Available from: https://dx.doi.org/10.1155/2021/3941923.

8) Jule LT, Ramaswamy K, Nagaprasad N, Shanmugam V, Vignesh V. Design and analysis of serial drilled hole in composite material. Materials Today: Proceedings. 2021;45:5759-5763. Available from: https://dx.doi.org/10.1016/j.matpr.2021.02.587.

9) Ltesfaye B, Bekele A, Saka N, Nagaprasad K, Sivaramasundaram R, Krishnaraj. Investigating spectroscopic and structural properties of Cr doped TiO2 NPs synthesized through sol gel deposition technique. Tierärztliche Praxis. 2021;41:860-872.

10) Raj A, Peskin CS, Tranchina D, Vargas DY, Tyagi S. Stochastic mRNA Synthesis in Mammalian Cells. PLoS Biology. 2006;4(10):e309. Available from: https://dx.doi.org/10.1371/journal.pbio.0040309.

11) Ghaffari-Moghaddam M, Hadi-Dabanlou R. Plant mediated green synthesis and antibacterial activity of silver nanoparticles using Crataegus douglasii fruit extract. Journal of Industrial and Engineering Chemistry. 2014;20(2):739-744. Available from: https://dx.doi.org/10.1016/j.jiec.2013.09.005.

12) Mahendra R, Nelson D. Metal Nanoparticles in Microbiology. Springer. 2011. Available from: https://www.springer.com/gp/book/9783642183119.

13) Hesgazy S, Lamis D, Shabaan GH, Rabie GH, Diana SR. Biosynthesis of silver nanoparticles using cell-free callus exudates of Medicago sativa. $L$ Pakistan Journal of Botany. 2015;47:1825-1829. Available from: https://www.pakbs.org/pjbot/PDFs/47(5)/28.pdf.

14) Srinivas B, Srikanth M, Prasanth S, Padma N. Green synthesis of silver nanoparticles using leaf extract and fruit pulp of Azadirachta indica. International Journal of Sciences \& Applied Research. 2017;4:49-56. Available from: https://www.ijsar.in/Admin/pdf/418.pdf. 
15) Asokan R, Dinesh M, Santosh R, Arumugam V, Stanley JA. Experimental Investigation of Failure Mechanisms in GFRP Lap Joint using Acoustic Emission. International Journal of Vehicle Structures and Systems. 2012;4:178-187. Available from: https://dx.doi.org/10.4273/ijvss.4.2.03.

16) Gardea-Torresdey JL, Gomez E, Peralta-Videa JR, Parsons JG, Troiani H, Jose-Yacaman M. Alfalfa Sprouts: A Natural Source for the Synthesis of Silver Nanoparticles. Langmuir. 2003;19(4):1357-1361. Available from: https://dx.doi.org/10.1021/la020835i.

17) Haverkamp RG, Marshall AT. The mechanism of metal nanoparticle formation in plants: limits on accumulation. Journal of Nanoparticle Research. 2009;11(6):1453-1463. Available from: https://dx.doi.org/10.1007/s11051-008-9533-6.

18) Ankamwar B, Chaudhary M, Sastry M. Gold Nanotriangles Biologically Synthesized using Tamarind Leaf Extract and Potential Application in Vapor Sensing. Synthesis and Reactivity in Inorganic, Metal-Organic, and Nano-Metal Chemistry. 2005;35:19-26. Available from: https://dx.doi.org/10.1081/ sim-200047527.

19) Vyom P, Parashar R, Sharma B, and AP. Partenium leaf extract mediated synthesis of silver nanoparticles: a novel approach towards weed utilization. Digest Journal of nanomaterials and biostructures. 2009;4:45-50.

20) Jule LT, Ramaswamy K, Bekele B, Saka A, Nagaprasad N. Experimental investigation on the impacts of annealing temperatures on titanium dioxide nanoparticles structure, size and optical properties synthesized through sol-gel methods. Materials Today: Proceedings. 2021;45:5752-5758. Available from: https://dx.doi.org/10.1016/j.matpr.2021.02.586.

21) Abel S, Tesfaye JL, Kiran R, Deepak T, Ruby AU, Venkatesh S, et al. Studying the Effect of Metallic Precursor Concentration on the Structural, Optical, and Morphological Properties of Zinc Sulfide Thin Films in Photovoltaic Cell Applications. Advances in Materials Science and Engineering. 2021;2021:1-6. Available from: https://dx.doi.org/10.1155/2021/7443664.

22) Lee D, Cohen RE, Rubner MF. Antibacterial Properties of Ag Nanoparticle Loaded Multilayers and Formation of Magnetically Directed Antibacterial Microparticles. Langmuir. 2005;21:9651-9659. Available from: https://dx.doi.org/10.1021/la0513306.

23) Panáček A, Kvítek L, Prucek R, Kolář M, Večeřová R, Pizúrová N, et al. Silver Colloid Nanoparticles: Synthesis, Characterization, and Their Antibacterial Activity. The Journal of Physical Chemistry B. 2006;110(33):16248-16253. Available from: https://dx.doi.org/10.1021/jp063826h.

24) Kassa B, Tesfaye JL, Bulcha B, Kiran R, Deepak T, Lal D, et al. Effect of Manganese Ions on Spectroscopic and Insulating Properties of Aluminophosphate Glasses. Advances in Materials Science and Engineering. 2021;2021:1-11. Available from: https://dx.doi.org/10.1155/2021/6253069.

25) Marambio-Jones C, Hoek EMV. A review of the antibacterial effects of silver nanomaterials and potential implications for human health and the environment. Journal of Nanoparticle Research. 2010;12(5):1531-1551. Available from: https://dx.doi.org/10.1007/s11051-010-9900-y.

26) Bondarenko O, Juganson $\mathrm{K}$, Ivask $\mathrm{A}$, Kasemets $\mathrm{K}$, Mortimer M, Kahru A. Toxicity of Ag, $\mathrm{CuO}$ and $\mathrm{ZnO}$ nanoparticles to selected environmentally relevant test organisms and mammalian cells in vitro: a critical review. Archives of Toxicology. 2013;87(7):1181-1200. Available from: https://dx.doi.org/10.1007/ s00204-013-1079-4.

27) Liu X, Shan K, Shao X, Shi X, He Y, Liu Z, et al. Nanotoxic Effects of Silver Nanoparticles on Normal HEK-293 Cells in Comparison to Cancerous HeLa Cell Line. International Journal of Nanomedicine. 2021;Volume 16:753-761. Available from: https://dx.doi.org/10.2147/ijn.s289008.

28) Coseri S, Spatareanu A, Sacarescu L, Rimbu C, Suteu D, Spirk S, et al. Green synthesis of the silver nanoparticles mediated by pullulan and 6carboxypullulan. Carbohydrate Polymers. 2015;116(13):9-17. Available from: https://dx.doi.org/10.1016/j.carbpol.2014.06.008.

29) Rai M, Yadav A, Gade A. Silver nanoparticles as a new generation of antimicrobials. Biotechnology Advances. 2009;27(1):76-83. Available from: https://dx.doi.org/10.1016/j.biotechadv.2008.09.002.

30) Ibrahim S, Ahmad Z, Manzoor MZ, Mujahid M, Faheem Z, Adnan A. Optimization for biogenic microbial synthesis of silver nanoparticles through response surface methodology, characterization, their antimicrobial, antioxidant, and catalytic potential. Scientific Reports. 2021;11(1). Available from: https://dx.doi.org/10.1038/s41598-020-80805-0.

31) Padma P, Banu S, Kumari S. Studies on Green Synthesis of Copper Nanoparticles Using Punica granatum. Annual Research \& Review in Biology. 2018;23(1):1-10. Available from: https://dx.doi.org/10.9734/arrb/2018/38894.

32) Nandal U, Bhardwaj RL. Aloe vera: a valuable wonder plant for food, medicine, and cosmetic use-a review. International Journal of Pharmaceutical Sciences Review and Research. 2012;p. 59-67. Available from: https://www.desertharvest.com/physicians/documents/General7.pdf.

33) Dang TMD, Le TTT, Fribourg-Blanc E, Dang MC. Synthesis and optical properties of copper nanoparticles prepared by a chemical reduction method. Advances in Natural Sciences: Nanoscience and Nanotechnology. 2011;2(1):015009. Available from: https://dx.doi.org/10.1088/2043-6262/2/1/015009.

34) Zhang Y, Yang D, Kong Y, Wang X, Pandoli O, Gao G. Synergetic Antibacterial Effects of Silver Nanoparticles@Aloe Vera Prepared via a Green Method. Nano Biomedicine and Engineering. 2010;2(4). Available from: https://dx.doi.org/10.5101/nbe.v2i4.p252-257.

35) Kim BH, Hackett MJ, Park J, Hyeon T. Synthesis, Characterization, and Application of Ultrasmall Nanoparticles. Chemistry of Materials. 2014;26(1):59-71. Available from: https://dx.doi.org/10.1021/cm402225z.

36) Kumar KH, Venkatesh N, Bhowmik H, Kuila A. Metallic Nanoparticle: A Review. Biomedical Journal of Scientific \& Technical Research. 2018. doi:10.26717/BJSTR.2018.04.001011.

37) Rucha MD, Venu G, Sanjeev K, Jha PK. Size Distribution of Silver Nanoparticles: UV-Visible Spectroscopic Assessment. Nanoscience and Nanotechnology Letters. 2012;(4):30-34. Available from: http://dx.doi.org/10.1166/nnl.2012.1278.

38) Huang H, Yang X. Synthesis of polysaccharide-stabilized gold and silver nanoparticles: a green method. Carbohydrate Research. 2004;339(15):2627-2631. Available from: https://dx.doi.org/10.1016/j.carres.2004.08.005.

39) Tippayawat P, Phromviyo N, Boueroy P, Chompoosor A. Green synthesis of silver nanoparticles in aloe vera plant extract prepared by a hydrothermal method and their synergistic antibacterial activity. PeerJ. 2016;4:e2589. Available from: https://dx.doi.org/10.7717/peerj.2589.

40) Velhal SG, Latpate RV, Kulkarni SD, Jaybhaye RG. Taguchi Design for Parameter Optimization of Size-Controlled Synthesis of Silver Nanoparticles. International Journal of Emerging Technologies in Computational and Applied Sciences. 2015;12:144-149.

41) Hungund BS. Comparative Evaluation of Antibacterial Activity of Silver Nanoparticles Biosynthesized Using Fruit Juices. Journal of Nanomedicine \& Nanotechnology. 2015;06(02):2-6. Available from: https://dx.doi.org/10.4172/2157-7439.1000271.

42) Balashanmugam P, Thangavelu KP. Biosynthesis characterization of silver nanoparticles using Cassia roxburghii DC. aqueous extract, and coated on cotton cloth for effective antibacterial activity. International Journal of Nanomedicine. 2015;10:87. Available from: https://dx.doi.org/10.2147/ijn.s79984.

43) Chitra K, Annadurai G. Antibacterial Activity of pH-Dependent Biosynthesized Silver Nanoparticles against Clinical Pathogen. BioMed Research International. 2014;2014:1-6. Available from: https://dx.doi.org/10.1155/2014/725165.

44) Baker C, Pradhan A, Pakstis L, Pochan D, Shah SI. Synthesis and Antibacterial Properties of Silver Nanoparticles. Journal of Nanoscience and Nanotechnology. 2005;5(2):244-249. Available from: https://dx.doi.org/10.1166/jnn.2005.034.

45) Othman AM, Elsayed MA, Al-Balakocy NG, Hassan MM, Elshafei AM. Biosynthesized silver nanoparticles by Aspergillus terreus NRRL265 for imparting durable antimicrobial finishing to polyester cotton blended fabrics: Statistical optimization, characterization, and antitumor activity evaluation. Biocatalysis 
and Agricultural Biotechnology. 2021;31:101908. Available from: https://dx.doi.org/10.1016/j.bcab.2021.101908.

46) Baptista PV, McCusker MP, Carvalho A, Ferreira DA, Mohan NM, Martins M, et al. Nano-Strategies to Fight Multidrug Resistant Bacteria-“A Battle of the Titans". Frontiers in Microbiology. 2018;9:1441. Available from: https://dx.doi.org/10.3389/fmicb.2018.01441. 